\title{
Detrital titanite petrochonology of Sierra Nevada modern sands: tracing local and regional-scale arc processes
}

\author{
A. R. C. KYLANDER-CLARK ${ }^{1}$ AND S. M. JOHNSTON ${ }^{2}$
}

${ }^{1}$ University California, Santa Barbara (akylander@ucsb.edu)

${ }^{2}$ California Polytechnic San Luis Obispo

(scjohnst@calpoly.edu)

This study explores the utility of detrital titanite petrochonology as a tool to investigate arc processes that operate on local- and regional scales using titanite derived from the Sierra Nevada Cretaceous batholith. To characterize the full range of titanite ages and trace-element compositions across the Cretaceous batholith, we collected four samples of modern sands from stream catchments dominated by exposures of the western Fine Gold Intrusive Suite (FGIS; ca. 120-110 Ma), the axial Yosemite Valley Intrusive Suite (YVIS; ca. 105-100 Ma), and the easterm Tuolumne Intrusive Suite (TIS; ca. 96-88 Ma).

A principle component analysis (PCA) yields $\sim 80 \%$ of the variability in 4 different components. Principle component 1 (55\% of the variability) is interpreted to represent fractionation at the local (plutonic) scale; the younger TIS is strongly grouped here, within a larger range displayed by older populations $(125-100 \mathrm{Ma}) . \mathrm{PC} 1$ is strongly controlled by MREE, HREE, Th, LREE, $\mathrm{Na}, \mathrm{Ta}, \mathrm{Nb}$, $\mathrm{Mn}$, and $\mathrm{Zr}$ that are positively correlated with each other and are negatively correlated to $\mathrm{V}$ and $\mathrm{W}$. The second component (PC2; 11\%) primarily separates the rocks from east and west; eastern samples contain high Sr, LREE, P, Mo, Th, and $\mathrm{Zr}$ and are low in Al, and HREE relative to those in the west. We interpret this to represent changes in the source magmas, as the arc migrated eastward throughout the Cretaceous, thus inheriting a more evolved signature during its ascent. Principle components 3 and 4 (7\% and 6\%, respectively) distinguish two processes that operated on early (ca. $95 \mathrm{Ma}$ ) and late (ca. $88 \mathrm{Ma}$ ) TIS rocks: younger titanite is high in $\mathrm{Sc}$, $\mathrm{Fe}, \mathrm{Mn}, \mathrm{Mg}, \mathrm{Na}, \mathrm{Al}$ (PC3) and $\mathrm{Sr}$ and $\mathrm{V}$ (PC4) and has low $\mathrm{P}$ $(\mathrm{PC} 3)$ and $\mathrm{W}, \mathrm{U}, \mathrm{Nb}, \mathrm{Hf}$ and $\mathrm{Pb}(\mathrm{PC} 4)$.

This study reveals that detrital titanite petrochronology can be used to track secular changes in chemical makeup of plutons throughout batholith construction. It records not only local-scale variations during crystallization, but also faithfully records regional-scale magmatic processes. 